\title{
Secondary Phosphine Oxide Functionalized Gold Clusters and their Application in Photoelectrocatalytic Hydrogenation Reactions
}

Yu Wang, ${ }^{1{ }^{*}}$ Xiao-He Liu, ${ }^{2 \ddagger}$ Rongbin Wang, ${ }^{3}$ Beatrice Cula, ${ }^{1}$ Zhe-Ning Chen, ${ }^{4 *}$ Qing-Yun Chen, ${ }^{2 *}$ Norbert Koch, ${ }^{3}$ Nicola Pinna ${ }^{1^{*}}$

Affiliation:

${ }^{1}$ Institut für Chemie and IRIS Adlershof, Humboldt-Universität zu Berlin, 12489 Berlin, Germany

${ }^{2}$ International Research Center for Renewable Energy (IRCRE), State Key Laboratory of Multiphase Flow in Power Engineering School of Energy and Power Engineering, Xi'an Jiaotong University, Xi'an 710049, P.R. China

${ }^{3}$ Institut für Physik and IRIS Adlershof, Humboldt-Universität zu Berlin, 12489 Berlin, Germany

${ }^{4}$ State Key Laboratory of Structural Chemistry, Fujian Institute of Research on the Structure of Matter, Chinese Academy of Sciences, Fuzhou 350002, P. R. China

${ }^{\ddagger}$ These authors contribute equally.

ABSTRACT: Ligands in ligand-protected metal clusters play a crucial role, not only because of their interaction with the metal core, but also because of the functionality they provide to the cluster. Here, we report the utilization of secondary phosphine oxide (SPO), as a new family of functional ligands, for the preparation of an undecagold cluster Au11-SPO. Different from the common used phosphine ligand (i.e. triphenylphosphine, TPP), the SPOs in Au11-SPO work as electron-withdrawing anionic ligands. While coordinating to gold via the phosphorus atom, the SPO ligand keeps its $O$ atom available to act as a nucleophile. Upon photoexcitation, the clusters are found to inject holes into $\mathrm{p}$ type semiconductors (here bismuth oxide is used as a model), sensitizing the $p$-type semiconductor in a different way compared to the photosensitization of a n-type semiconductor. Furthermore, the Au11-SPO $/ \mathrm{Bi}_{2} \mathrm{O}_{3}$ photocathode exhibits a much higher activity towards the hydrogenation of benzaldehyde than a TPP-protected $\mathrm{Au}_{11}$ sensitized $\mathrm{Bi}_{2} \mathrm{O}_{3}$ photocathode. Control experiments and density functional theory studies point to the crucial role of the cooperation between gold and the SPO ligands on the selectivity towards the hydrogenation of the $\mathrm{C}=0$ group in benzaldehyde.

Catalysis by gold clusters in the nanometric and sub-nanometric regime has drawn enormous attentions since the seminal works by Haruta and Hutchings in the $1980 \mathrm{~s}^{1-4}$ Both bare gold clusters formed in gas-phase and ligand-protected gold clusters prepared by wet chemistry methods are widely utilized in catalysis and they exhibit promising activities. ${ }^{5-12}$ For example, the well-known $\mathrm{Au}_{55}\left(\mathrm{PPh}_{3}\right)_{12} \mathrm{Cl}_{6}$, first reported by Schmid in 1981, exhibits good stability against oxidation, and its derived catalyst supported on $\mathrm{SiO}_{2}$ can effectively and selectively catalyze the oxidation of styrene by atomic oxygen. ${ }^{6,9}$ Mass-selected $\mathrm{Au}_{8}$ clusters, deposited on $\mathrm{MgO}$, can oxidize $\mathrm{CO}$ at a low temperature. ${ }^{7}$ While the application of gold catalysts in oxidation reactions has been extensively explored, there are only few reports on gold catalysts for hydrogenation reactions, largely due to the inferior capacity of gold to dissociate hydrogen, compared to other noble metals such as $\mathrm{Pt}$ and $\mathrm{Pd} .{ }^{13-}$

${ }^{18}$ Recently, Secondary phosphine oxide (SPO) stabilized gold nanoparticles have shown good activity and high selectivity for aldehyde hydrogenation. ${ }^{19,20}$ The Au-P-O moieties on the surface of the nanoparticles serve as frustrated Lewis pairs and are proposed to have special ability to cleave $\mathrm{H}_{2}{ }^{21}$ Such kind of functionalized ligand has not been described as stabilizing agent in magic-number gold clusters. The structural determination of SPO protected gold clusters is vital as they could provide an ideal platform for a deeper understanding of structure-activity correlation of gold clusters. 
Besides the catalytic activities, gold clusters also exhibit good light absorption abilities due to their discrete energy levels. ${ }^{22-24}$ Thiolate-protected gold clusters have been employed as photosensitizers in photocatalytic systems. ${ }^{25-33}$ The sensitization of large band gap semiconductor, such as $\mathrm{TiO}_{2}$, with gold clusters has extended the photo response of $\mathrm{TiO}_{2}$, enabling visible-light-driven hydrogen evolution. ${ }^{27,34}$ These seminal studies mainly focus on the injection of electrons from the excited states of the clusters to the n-type semiconductors. On the other hand, it is unclear that would happen if the clusters are deposited on a p-type semiconductor. Moreover, mechanistic studies devoted to the elucidation of the role of gold clusters in photocatalysis are still scarce and are needed especially because of the dual role, as catalyst and photosensitizer, they can cover.

Herein, we report the first example of SPO-stabilized gold cluster. $\mathrm{Au}_{11}\left(\mathrm{PPh}_{2} \mathrm{O}\right)_{10}$ (denoted as Au11SPO) clusters with ten functional SPO ligands have been prepared, and structurally characterized. Different from the common used phosphine ligands, the SPOs serve as anionic ligands. The deposition of Au11-SPO onto p-type bismuth oxide extends the photoresponse of bismuth oxide in the visible region, suggesting the successful photosensitization. Furthermore, the as-prepared photocathode can readily reduce benzaldehyde to benzyl alcohol without additional $\mathrm{H}_{2}$ supply, which further verifies the catalytic role of Au11-SPO clusters.

The preparation of Au11-SPO started with the reduction of gold precursor by $\mathrm{NaBH}_{4}$ in THF solution (See supporting information for details). X-ray crystallographic analysis revealed that Au11SPO was crystallized in the monoclinic space groups $P 2_{1}$ (Table S1 and Figure S1). As illustrated in Figure 1, the core of Au11-SPO can be described as a bicapped, vertex-sharing, bi-triangularbipyramid. For clarity, triangular-bipyramids and capped gold atoms are highlighted in orange and green, respectively. The arrangement of gold atoms in Au11-SPO is different from that in the triphenylphosphine-protected $\mathrm{Au}_{11}\left(\mathrm{PPh}_{3}\right)_{8} \mathrm{Cl}_{2}$ (denoted as Au11-TPP), which is a substructure of icosahedral $\mathrm{Au}_{13}{ }^{35}$ The mean Au-Au bond length amounts to $2.8103 \AA$, which is in good agreement with the report data in literature for similar clusters. ${ }^{36-38}$ Except the sharing vertex gold, all the other ten gold atoms in Au11-SPO bind to ten SPO ligands, forming Au-PPh $\mathrm{O}_{2} \mathrm{O}$ coordination modes. The average length of $\mathrm{P}-\mathrm{O}$ bond is $1.55 \AA$, indicating the double bond between $\mathrm{P}$ and $\mathrm{O}$ atoms. ${ }^{39}$ Attenuated total reflection-infrared (ATR-IR) spectroscopic study showed that the P-H stretching absorption in free SPO was absent in Au11-SPO (Figure 2a). Thus, the SPO here works as anionic ligand, which is different from the phosphine and $\mathrm{N}$-heterocyclic carbene ligands in previously reported gold nanoclusters. ${ }^{19,40-42}$ The $\mathrm{O}$ atom on SPO can readily serve as nucleophile, making Au11SPO a functionalized cluster. ${ }^{43}$ The accessibility of Au sites in the cluster was evaluated by the hydrogenation of 4-nitrophenol, and the results indicate that small molecules can readily access the Au sites (Figure S2).

Since no unambiguous counter ions were identified in the single crystal of Au11-SPO, we tried to carry out mass spectrometry measurements to evaluate the charge state of Au11-SPO. Unfortunately, only fragments of the cluster were found. The charge state of Au11-SPO was confirmed by comparing the UV-Vis spectra to time-dependent density functional theory (TD-DFT) calculations. Three closed-shell Au11-SPO models that carry $+1,+3$ and -1 charges respectively, were considered. As shown in Figure 2b, the experimental UV-Vis spectrum of Au11-SPO shows two peaks at 416 and $557 \mathrm{~nm}$. Comparison of the computed spectra for Au11-SPO carrying $+1,+3$ and -1 charges to the experimental spectrum reveals that the calculated spectrum for the mono-cationic Au11-SPO is in good agreement with the experimental one, even though slight shifts in the peak positions are observed (Figures $2 \mathrm{~b}$ and S3). Furthermore, the average Au-Au distance in the optimized monocationic Au11-SPO corresponded much better to the experimental value as compared to the other two (Table S2). The results indicate that the stable Au11-SPO cluster should carry a +1 charge. 
$\alpha-\mathrm{Bi}_{2} \mathrm{O}_{3}$ was used as a model support for the deposition of Au11-SPO (Figure S4). The good lightabsorption ability and p-type property make $\mathrm{Bi}_{2} \mathrm{O}_{3}$ a promising photocathode material, where photoexcited electrons stay for reduction reactions. ${ }^{44}$ The UV-Vis spectrum of Au11-SPO/ $\mathrm{Bi}_{2} \mathrm{O}_{3}$ showed enhanced absorption in the visible region, indicating the successful deposition of Au11-SPO (Figure S5). Photoelectron spectroscopy was conducted to assess the electronic properties of the Au11-SPO/ $\mathrm{Bi}_{2} \mathrm{O}_{3}$ composite (Figure S6). The secondary electron cutoffs (SECOs), before and after the deposition of Au11-SPO, were determined as $4.2 \mathrm{eV}$ and $3.6 \mathrm{eV}$, respectively. The valence band maximum (VBM) of $\mathrm{Bi}_{2} \mathrm{O}_{3}$ and the highest occupied molecular orbital (HOMO) of Au11-SPO are 1.23 and $1.86 \mathrm{eV}$, respectively, with respect to the Fermi level $\left(\mathrm{E}_{\mathrm{F}}\right) .{ }^{45}$ The energy level diagram indicates a staggered structure at the interface (Figure 3a). Our previous study demonstrated that atomically precise metal nanoclusters with distinct HOMO-LUMO (lowest unoccupied molecular orbital) gap can be treated as small band-gap semiconductors. ${ }^{46}$ Here, a type II photosystem was built upon the deposition of Au11-SPO onto $\mathrm{Bi}_{2} \mathrm{O}_{3}$. As shown in Figure $3 \mathrm{~b}$, when both $\mathrm{Bi}_{2} \mathrm{O}_{3}$ and Au11-SPO are excited, the photoinduced electrons in the conduction band (CB) of $\mathrm{Bi}_{2} \mathrm{O}_{3}$ will transfer to the LUMO of Au11-SPO and, simultaneously, holes in the HOMO of Au11-SPO will inject into the valence band (VB) of $\mathrm{Bi}_{2} \mathrm{O}_{3}$. This process is expected to reduce the resistance to charge transfer and improve the efficiency of the charge separation.

Photoelectrochemical measurements were carried out to verify the charge transfers at the interface. The photocurrent response of Au11-SPO/ $\mathrm{Bi}_{2} \mathrm{O}_{3}$ under on-off cycles of $565 \mathrm{~nm}$ light illumination is shown in Figure S7. As pristine $\mathrm{Bi}_{2} \mathrm{O}_{3}$ doesn't respond to the most part of visible light due to its relatively large band gap, the photoresponse can be attributed to the Au11-SPO only (Figure S5b). This suggests that Au11-SPO can act as the photosensitizer in a p-type semiconductor based system. It should be noted that the charge transfer pathway here is different from that of the previously reported n-type semiconductor based systems (Figure S8b). ${ }^{27,46}$ Under visible light, only the electrons-hole pairs in Au11-SPO are excited. As the energy level of the HOMO is lower than the $\mathrm{VB}$ of $\mathrm{Bi}_{2} \mathrm{O}_{3}$, the holes in the clusters are transferred to $\mathrm{Bi}_{2} \mathrm{O}_{3}$, collected and transferred through the external circuit to the counter electrode to induce the oxidation reactions. The photoinduced electrons, at the same time, assemble at the photocathode for reduction reactions.

Given the good catalytic properties of gold nanoparticles and the readily accessible $\mathrm{Au}$ sites in Au11-SPO, we further explored the possibility of using Au11-SPO/ $\mathrm{Bi}_{2} \mathrm{O}_{3}$ photocathode in a photoelectrochemical cell for the coupling of water oxidation and benzaldehyde hydrogenation. Figure 4a depicts the conversion of benzaldehyde by pristine $\mathrm{Bi}_{2} \mathrm{O}_{3}$ photocathode (blue curve) and Au11-SPO $/ \mathrm{Bi}_{2} \mathrm{O}_{3}$ (red curve) with a bias range from 0 to $-0.5 \mathrm{~V}$ versus $\mathrm{Ag} / \mathrm{AgCl}$. While pristine $\mathrm{Bi}_{2} \mathrm{O}_{3}$ showed poor activity, the Au11-SPO/ $\mathrm{Bi}_{2} \mathrm{O}_{3}$ photocathode showed very high activities at all bias employed, indicating the importance of the Au11-SPO clusters.

The role of Au11-SPO in the catalytic hydrogenation of ben-zaldehyde was then investigated by DFT calculations. Hydrogenated species are generally considered as the intermediate in photoelectrochemical hydrogen evolution. ${ }^{47}$ The hydrogenated Au11-SPO species were thus used as the starting reagent for the benzaldehyde hydrogenation, as well as the hydrogen evolution. As shown in Figure 4c, two different hydrogenated Au11-SPO intermediates were considered, where two heterolytic hydrogens bonded to $\mathrm{Au}$ and $\mathrm{O}$ atoms respectively (LM1), or two homolytic hydrogens both bonded to $\mathrm{Au}$ atoms (LM2). Our calculations showed that the heterolytic hydrogenated Au11-SPO species is much more favorable than the homolytic hydrogenated one (LM1 vs LM2: 0.0 vs $34.6 \mathrm{kcal} / \mathrm{mol}$ ), suggesting that the heterolytic hydrogenated Au11-SPO species should exist as the predominant hydrogenated intermediate. The heterolytic hydrogenated Au11-SPO species showed a kinetic selectivity towards benzaldehyde hydrogenation against hydrogen evolution (TS1 vs TS1': 22.0 vs $25.6 \mathrm{kcal} / \mathrm{mol}$ ), indicating the high activity for a couple of heterolytic 
hydrogens in polar $\mathrm{C}=\mathrm{O}$ bond reduction. In contrast, the homolytic hydrogenated Au11-SPO species displayed an obvious kinetic advantage towards hydrogen evolution (free energy barriers of TS2 vs TS2': 2.2 vs $26.5 \mathrm{kcal} / \mathrm{mol}$ ). These findings clearly indicates that the cooperation between the Au and SPO ligand plays a key role for the generation of the heterolytic hydrogenated species, promoting the selectivity towards polar $\mathrm{C}=\mathrm{O}$ bond reduction. Whereas in absence of the SPO ligand, homolytic hydrogenated species are generated instead, selectivity would thus tend to hydrogen evolution.

To verify the important role of the SPO ligand, the Au11-TPP sensitized $\mathrm{Bi}_{2} \mathrm{O}_{3}$ photocathode was prepared and tested. In the absence of benzaldehyde, the photocurrents generated by Au11$\mathrm{TPP} / \mathrm{Bi}_{2} \mathrm{O}_{3}$ and Au11-SPO/ $/ \mathrm{Bi}_{2} \mathrm{O}_{3}$ were comparable, indicating the similar sensitization abilities of Au11-TPP and Au11-SPO (Figure S9). In the presence of benzaldehyde, Au11-TPP $/ \mathrm{Bi}_{2} \mathrm{O}_{3}$ showed a much lower activity for benzaldehyde hydrogenation than Au11-SPO/ $\mathrm{Bi}_{2} \mathrm{O}_{3}$ at all bias employed (Figures 4a, magenta curve). Instead of catalyzing benzaldehyde hydrogenation, Au11-TPP/ $\mathrm{Bi}_{2} \mathrm{O}_{3}$ exhibited good hydrogen production ability (Figure S10). As there was no big difference on the sensitization ability and stability between Au11-SPO and Au11-TPP (Figures $4 \mathrm{~b}$ and S9), the higher selectivity towards benzaldehyde hydrogenation by $\mathrm{Au11}-\mathrm{SPO} / \mathrm{Bi}_{2} \mathrm{O}_{3}$ was attributed to the functional SPO ligand and its cooperation with $\mathrm{Au}$, which is in good agreement with the DFT calculated results.

In summary, secondary phosphine oxide ligands were successfully employed as anionic protecting agents for gold nanoclusters. The obtained Au11-SPO is structurally characterized and a bicapped, vertex-sharing, bi-triangular-bipyramid metal core is revealed. Upon photoexcitation, Au11-SPO injects holes to the $\mathrm{VB}$ of $\mathrm{Bi}_{2} \mathrm{O}_{3}$, sensitizing the $\mathrm{p}$-type semiconductor in a different way compared to n-type semiconductors. The catalytic role of Au11-SPO is confirmed by the photoelectrochemical hydrogenation of benzaldehyde. The superior performance of Au11-SPO/ $\mathrm{Bi}_{2} \mathrm{O}_{3}$ compared to Au11$\mathrm{TPP} / \mathrm{Bi}_{2} \mathrm{O}_{3}$ is attributed to the Au-P-O moieties. These observations suggest that SPO are promising functional ligands for cluster stabilization. We expect that this work will stimulate more research interests on the preparation of functionalized metal nanoclusters, the study of catalytic cooperative effects and their applications in photoelectrocatalysis.

\section{ACKNOWLEDGMENT}

We are grateful to the German Research Foundation (DFG, project number 456075917) for financial support. Q. C. thanks the support from Nature Science Foundation of China (No. 21878242, No. 21828802). Z.-N.C. thanks the support from National Natural Science Foundation of China (No. 21973094).

\section{REFERENCES}

(1) Hutchings, G. J. Vapor Phase Hydrochlorination of Acetylene: Correlation of Catalytic Activity of Supported Metal Chloride Catalysts. J. Catal. 1985, 96, 292.

(2) Haruta, M.; Yamada, N.; Kobayashi, T.; lijima, S. Gold Catalysts Prepared by Coprecipitation for Lowtemperature Oxidation of Hydrogen and of Carbon Monoxide. J. Catal. 1989, 115, 301.

(3) Meyer, R.; Lemire, C.; Shaikhutdinov, S. K.; Freund, H. J. Surface Chemistry of Catalysis by Gold. Gold Bull. 2004, 37, 72.

(4) Boronat, M.; Leyva-Pérez, A.; Corma, A. Theoretical and Experimental Insights into the Origin of the Catalytic Activity of Subnanometric Gold Clusters: Attempts to Predict Reactivity with Clusters and Nanoparticles of Gold. Acc. Chem. Res. 2014, 47, 834.

(5) Sanchez, A.; Abbet, S.; Heiz, U.; Schneider, W. D.; Häkkinen, H.; Barnett, R. N.; Landman, U. When Gold Is Not Noble: Nanoscale Gold Catalysts. J. Phys. Chem. A 1999, 103, 9573. 
(6) Boyen, H.-G.; Kästle, G.; Weigl, F.; Koslowski, B.; Dietrich, C.; Ziemann, P.; Spatz, J. P.; Riethmüller, S.; Hartmann, C.; Möller, M.; Schmid, G.; Garnier, M. G.; Oelhafen, P. Oxidation-Resistant Gold-55 Clusters. Science 2002, 297, 1533.

(7) Yoon, B.; Häkkinen, H.; Landman, U.; Wörz, A. S.; Antonietti, J.-M.; Abbet, S.; Judai, K.; Heiz, U. Charging Effects on Bonding and Catalyzed Oxidation of $\mathrm{CO}$ on $\mathrm{Au}_{8}$ Clusters on MgO. Science 2005, 307, 403.

(8) Herzing, A. A.; Kiely, C. J.; Carley, A. F.; Landon, P.; Hutchings, G. J. Identification of Active Gold Nanoclusters on Iron Oxide Supports for CO Oxidation. Science 2008, 321, 1331.

(9) Turner, M.; Golovko, V.; Vaughan, O; Abdulkin, P.; Berenguer-Murcia, A.; Tikhov, M. S.; Johnson, B. F. G.; Lambert, R. M. Selective Oxidation with Dioxygen by Gold Nanoparticle Catalysts Derived from 55-atom Clusters. Nature 2008, 454, 981.

(10) Li, G.; Jin, R. Atomically Precise Gold Nanoclusters as New Model Catalysts. Acc. Chem. Res. 2013, 46, 1749.

(11) Kettemann, F.; Witte, S.; Birnbaum, A.; Paul, B.; Clavel, G.; Pinna, N.; Rademann, K.; Kraehnert, R.; Polte, J. Unifying Concepts in Room-Temperature CO Oxidation with Gold Catalysts. ACS Catal. 2017, 7, 8247.

(12) Jin, R.; Li, G.; Sharma, S.; Li, Y.; Du, X. Toward Active-Site Tailoring in Heterogeneous Catalysis by Atomically Precise Metal Nanoclusters with Crystallographic Structures. Chem. Rev. 2020, DOI: 10.1021/acs.chemrev.0c00495

(13) Zhu, Y.; Qian, H.; Drake, B. A.; Jin, R. Atomically Precise $A_{u_{25}}(\mathrm{SR})_{18}$ Nanoparticles as Catalysts for the Selective Hydrogenation of $\alpha, \beta$-Unsaturated Ketones and Aldehydes. Angew. Chem. Int. Ed. 2010, 49, 1295.

(14) Yamazoe, S.; Koyasu, K.; Tsukuda, T. Nonscalable Oxidation Catalysis of Gold Clusters. Acc. Chem. Res. 2014, $47,816$.

(15) Wan, X.-K.; Wang, J.-Q.; Nan, Z.-A.; Wang, Q.-M. Ligand Effects in Catalysis by Atomically Precise Gold Nanoclusters. Sci. Adv. 2017, 3, e1701823.

(16) Zhimin, L.; Hadi, A.; Chao, L.; Gao, L. A Critical Review on the Catalytic Applications of Non-Metallic Gold Nanoclusters: Selective Oxidation, Hydrogenation, and Coupling Reactions. Curr. Org. Chem. 2017, $21,476$.

(17) Tian, S.; Cao, Y.; Chen, T.; Zang, S.; Xie, J. Ligand-protected Atomically Precise Gold Nanoclusters as Model Catalysts for Oxidation Reactions. Chem. Commun. 2020, 56, 1163.

(18) Zhao, Y.; Zhuang, S.; Liao, L.; Wang, C.; Xia, N.; Gan, Z.; Gu, W.; Li, J.; Deng, H.; Wu, Z. A Dual Purpose Strategy to Endow Gold Nanoclusters with Both Catalysis Activity and Water Solubility. J. Am. Chem. Soc. 2020, $142,973$.

(19) Cano, I.; Chapman, A. M.; Urakawa, A.; van Leeuwen, P. W. N. M. Air-Stable Gold Nanoparticles Ligated by Secondary Phosphine Oxides for the Chemoselective Hydrogenation of Aldehydes: Crucial Role of the Ligand. J. Am. Chem. Soc. 2014, 136, 2520.

(20) Cano, I.; Huertos, M. A.; Chapman, A. M.; Buntkowsky, G.; Gutmann, T.; Groszewicz, P. B.; van Leeuwen, P. W. N. M. Air-Stable Gold Nanoparticles Ligated by Secondary Phosphine Oxides as Catalyst for the Chemoselective Hydrogenation of Substituted Aldehydes: a Remarkable Ligand Effect. J. Am. Chem. Soc. 2015, $137,7718$.

(21) Almora-Barrios, N.; Cano, I.; van Leeuwen, P. W. N. M.; López, N. Concerted Chemoselective Hydrogenation of Acrolein on Secondary Phosphine Oxide Decorated Gold Nanoparticles. ACS Catal. 2017, 7, 3949.

(22) Häkkinen, H.; Yoon, B.; Landman, U.; Li, X.; Zhai, H.-J.; Wang, L.-S. On the Electronic and Atomic Structures of Small AuN- ( $\mathrm{N}=4-14)$ Clusters: A Photoelectron Spectroscopy and Density-Functional Study. J. Phys. Chem. A 2003, 107, 6168.

(23) Aikens, C. M. Electronic and Geometric Structure, Optical Properties, and Excited State Behavior in Atomically Precise Thiolate-Stabilized Noble Metal Nanoclusters. Acc. Chem. Res. 2018, 51, 3065.

(24) Tang, Q.; Hu, G.; Fung, V.; Jiang, D.-e. Insights into Interfaces, Stability, Electronic Properties, and Catalytic Activities of Atomically Precise Metal Nanoclusters from First Principles. Acc. Chem. Res. 2018, 51, 2793.

(25) Kogo, A.; Sakai, N.; Tatsuma, T. Photoelectrochemical Analysis of Size-dependent Electronic Structures of Gold Clusters Supported on $\mathrm{TiO}_{2}$. Nanoscale 2012, 4, 4217. 
(26) $\mathrm{Yu}, \mathrm{C}$; $\mathrm{Li}, \mathrm{G} . ;$ Kumar, S.; Kawasaki, H.; Jin, R. Stable $\mathrm{Au}_{25}(\mathrm{SR})_{18} / \mathrm{TiO}_{2}$ Composite Nanostructure with Enhanced Visible Light Photocatalytic Activity. J. Phys. Chem. Lett. 2013, 4, 2847.

(27) Chen, Y.-S.; Kamat, P. V. Glutathione-Capped Gold Nanoclusters as Photosensitizers. Visible Light-Induced Hydrogen Generation in Neutral Water. J. Am. Chem. Soc. 2014, 136, 6075.

(28) Xiao, F.-X.; Zeng, Z.; Liu, B. Bridging the Gap: Electron Relay and Plasmonic Sensitization of Metal Nanocrystals for Metal Clusters. J. Am. Chem. Soc. 2015, 137, 10735.

(29) Azarias, C.; Adamo, C.; Perrier, A. Modeling the Photosensitizing Properties of Thiolate-protected Gold Nanoclusters. Phys. Chem. Chem. Phys. 2016, 18, 7737.

(30) Liu, Y.; Yao, Q.; Wu, X.; Chen, T.; Ma, Y.; Ong, C. N.; Xie, J. Gold Nanocluster Sensitized $\mathrm{TiO}_{2} \mathrm{Nanotube}$ Arrays for Visible-light Driven Photoelectrocatalytic Removal of Antibiotic Tetracycline. Nanoscale 2016, 8, 10145.

(31) Abbas, M. A.; Kamat, P. V.; Bang, J. H. Thiolated Gold Nanoclusters for Light Energy Conversion. ACS Energy Lett. 2018, 3, 840 .

(32) Weng, B.; Lu, K.-Q.; Tang, Z.; Chen, H. M.; Xu, Y.-J. Stabilizing Ultrasmall Au Clusters for Enhanced Photoredox Catalysis Nat. Commun. 2018, 9, 1543.

(33) Kawawaki, T.; Negishi, Y.; Kawasaki, H. Photo/Electrocatalysis and Photosensitization Using Metal Nanoclusters for Green Energy and Medical Applications. Nanoscale Adv. 2020, 2, 17.

(34) Wang, Y.; Liu, X.-H.; Kovalenko, S. A.; Chen, Q.-Y.; Pinna, N. Atomically Precise Bimetallic Nanoclusters as Photosensitizers in Photoelectrochemical Cells. Chem. Eur. J. 2019, 25, 4814.

(35) McKenzie, L. C.; Zaikova, T. O.; Hutchison, J. E. Structurally Similar Triphenylphosphine-Stabilized Undecagolds, $\mathrm{Au}_{11}\left(\mathrm{PPh}_{3}\right)_{7} \mathrm{Cl}_{3}$ and $\left[\mathrm{Au}_{11}\left(\mathrm{PPh}_{3}\right)_{8} \mathrm{Cl}_{2}\right] \mathrm{Cl}$, Exhibit Distinct Ligand Exchange Pathways with Glutathione. J. Am. Chem. Soc. 2014, 136, 13426.

(36) Gutrath, B. S.; Englert, U.; Wang, Y.; Simon, U. A Missing Link in Undecagold Cluster Chemistry: SingleCrystal X-ray Analysis of $\left[\mathrm{Au}_{11}\left(\mathrm{PPh}_{3}\right)_{7} \mathrm{Cl}_{3}\right]$. Eur. J. Inorg. Chem. 2013, 2013, 2002.

(37) Kang, X.; Song, Y.; Deng, H.; Zhang, J.; Liu, B.; Pan, C.; Zhu, M. Ligand-induced Change of the Crystal Structure and Enhanced Stability of the $\mathrm{Au}_{11}$ Nanocluster. RSC Adv. 2015, 5, 66879.

(38) Yao, L.-Y.; Yam, V. W.-W. Diphosphine-Stabilized Small Gold Nanoclusters: From Crystal Structure Determination to Ligation-Driven Symmetry Breaking and Anion Exchange Properties. J. Am. Chem. Soc. 2016, $138,15736$.

(39) Gamoke, B.; Neff, D.; Simons, J. Nature of PO Bonds in Phosphates. J. Phys. Chem. A 2009, 113, 5677.

(40) Konishi, K.; Iwasaki, M.; Shichibu, Y. Phosphine-Ligated Gold Clusters with Core+exo Geometries: Unique Properties and Interactions at the Ligand-Cluster Interface. Acc. Chem. Res. 2018, 51, 3125.

(41) Shen, H.; Deng, G.; Kaappa, S.; Tan, T.; Han, Y.-Z.; Malola, S.; Lin, S.-C.; Teo, B. K.; Häkkinen, H.; Zheng, N. Highly Robust but Surface-Active: An N-Heterocyclic Carbene-Stabilized $\mathrm{Au}_{25}$ Nanocluster. Angew. Chem. Int. Ed. 2019, 58, 17731.

(42) Narouz, M. R.; Osten, K. M.; Unsworth, P. J.; Man, R. W. Y.; Salorinne, K.; Takano, S.; Tomihara, R.; Kaappa, S.; Malola, S.; Dinh, C.-T.; Padmos, J. D.; Ayoo, K.; Garrett, P. J.; Nambo, M.; Horton, J. H.; Sargent, E. H.; Häkkinen, H.; Tsukuda, T.; Crudden, C. M. N-heterocyclic Carbene-Functionalized Magic-Number Gold Nanoclusters. Nat. Chem.2019, 11, 419.

(43) van Leeuwen, P. W. N. M; Cano, I.; Freixa, Z. Secondary Phosphine Oxides: Bifunctional Ligands in Catalysis. ChemCatChem. 2020, 12, 3982.

(44) Hameed, A.; Montini, T.; Gombac, V.; Fornasiero, P. Surface Phases and Photocatalytic Activity Correlation of $\mathrm{Bi}_{2} \mathrm{O}_{3} / \mathrm{Bi}_{2} \mathrm{O}_{4-x}$ Nanocomposite. J. Am. Chem. Soc. 2008, 130, 9658.

(45) Wang, R.; Wang, Y.; Wu, C.; Zhai, T.; Yang, J.; Sun, B.; Duhm, S.; Koch, N. Direct Observation of Conductive Polymer Induced Inversion Layer in n-Si and Correlation to Solar Cell Performance. Adv. Funct. Mater. 2020, 30, 1903440. 
(46) Wang, Y.; Liu, X.-H.; Wang, Q.; Quick, M.; Kovalenko, S. A.; Chen, Q.-Y.; Koch, N.; Pinna, N. Insights into Charge Transfer at an Atomically Precise Nanocluster/Semiconductor Interface. Angew. Chem. Int. Ed. 2020, 59, 7748.

(47) Pastor, E.; Formal. F.; Mayer, T. M.; Tilley, S. D.; Francàs, L.; Mesa, A. C.; Grätzel, M.; Durrant, R. J. Spectroelectrochemical Analysis of the Mechanism of (Photo)electrochemical Hydrogen Evolution at a Catalytic Interface. Nat. Commun. 2017, 8, 14280.
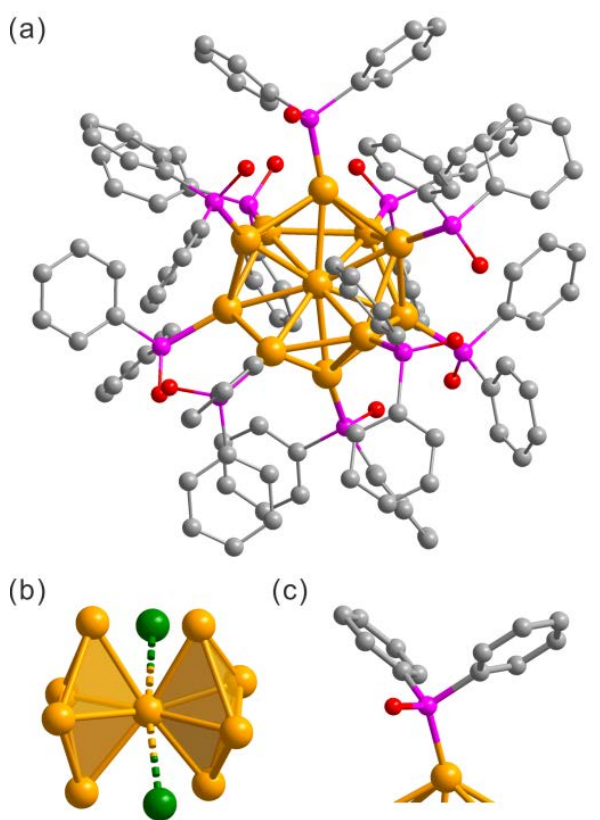

Figure 1. (a) The crystal structure, (b) the gold core and (c) the Au-SPO moiety of Au11-SPO. Color legend: orange sphere, $\mathrm{Au}$; green sphere, capping $\mathrm{Au}$; purple sphere, $\mathrm{P}$; red sphere, O; grey sphere, C. All hydrogen atoms are omitted for clarity.
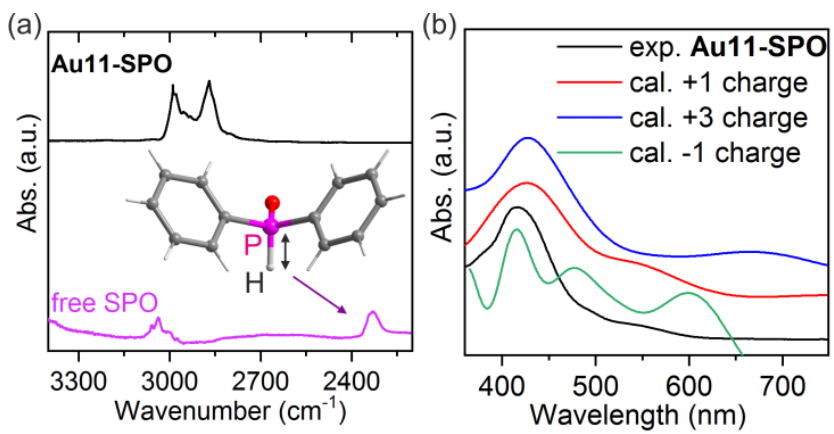

Figure 2. (a) ATR FT-IR spectra of the free SPO and Au11-SPO. (b) Experimental and simulated UV-Vis absorption spectra of Au11-SPO. The slight shifts in the calculated UV-Vis absorption spectra were corrected for better comparison. See SI for the uncorrected data. 
(a)

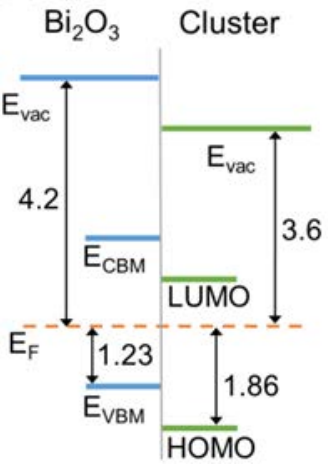

(b)

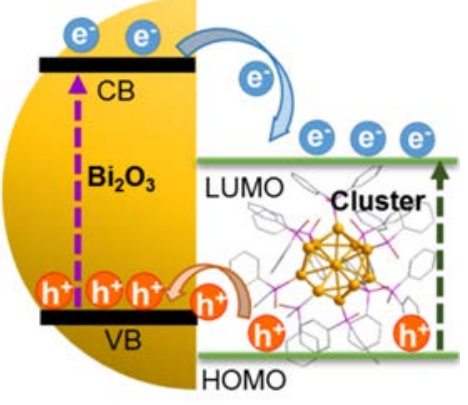

Figure 3. (a) Schematic energy level diagram after the deposition of Au11-SPO onto $\mathrm{Bi}_{2} \mathrm{O}_{3}$. (b) Schematic illustration of the charge transfer pathway upon illumination.
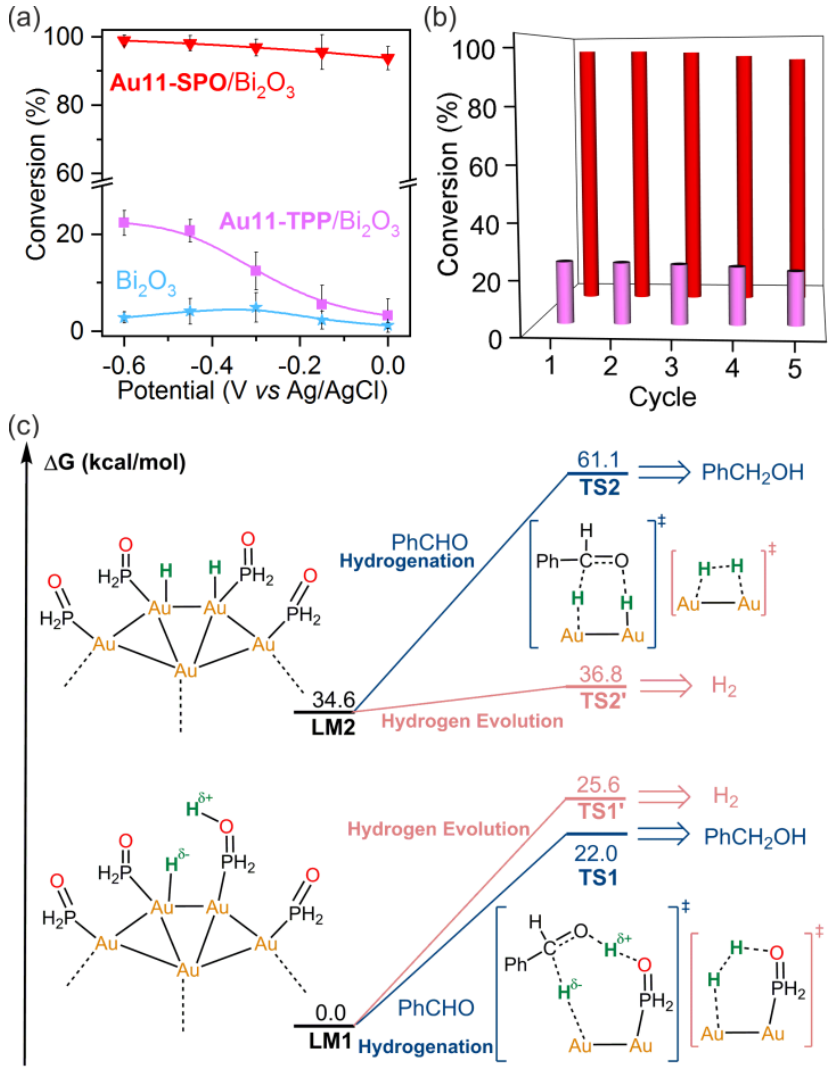

Figure 4. (a) Catalytic activities of $\mathrm{Bi}_{2} \mathrm{O}_{3}$ (Blue), Au11-TPP $/ \mathrm{Bi}_{2} \mathrm{O}_{3}$ (Magenta) and Au11-SPO/ $/ \mathrm{Bi}_{2} \mathrm{O}_{3}$ (Red) photocathodes for the hydrogenation of benzaldehyde at varying bias potentials. Condition: $0.1 \mathrm{mM}$ benzaldehyde in phosphate saline buffer $(\mathrm{pH}=7)$; simulated solar light; $0.5 \mathrm{~h}$ duration. (b) 
Recyclability of Au11-TPP $/ \mathrm{Bi}_{2} \mathrm{O}_{3}$ (Magenta) and Au11-SPO/ $\mathrm{Bi}_{2} \mathrm{O}_{3}$ (Red). (c) DFT calculated reaction kinetics for benzaldehyde hydrogenation as well as hydrogen evolution from different hydrogenated Au11-SPO intermediates. 